\title{
Cavum velum interpositum, cavum septum pellucidum and cavum Vergae: a review
}

\author{
Maciej K. Ciołkowski
}

Received: 13 July 2011 / Accepted: 11 August 2011 /Published online: 10 September 2011

(C) The Author(s) 2011. This article is published with open access at Springerlink.com

Dear Editor,

I read with interest the recent paper presented by Shane Tubbs et al. [1] where they gave comprehensive and clear description of congenital supratentorial midline fluid spaces not belonging to the ventricular system. Unfortunately, well-selected pictures received erroneous legends. Figure 1 presents in fact an axial computed tomography (CT) scan, Fig. 2 an axial magnetic resonance imaging (MRI) study, Fig. 3 a coronal MRI noting cavum septi pellucidi at the level suggesting it may be continuous with cavum Vergae and Fig. 4 an axial CT scan. In Fig. 5, which is an axial CT scan, the presence of the cavum septi pellucidi is obvious, but tortuous course and termination within the tip of tentorial notch of the walls of supposed cavum Vergae suggest rather these could be internal cerebral veins.

Within the region of the velum interpositum or transverse cerebral fissure, three paired structures can be visualised in imaging studies: crura of fornices, internal cerebral veins and thalamic striae with choroid plexus of the third ventricle (Fig. 1). Very often the diverging crura of fornices under the splenium of corpus callosum are captured on the axial pictures as formation resembling reversed letter Y (Fig. 1c) and they should not be confused with cavum Vergae (Fig. 1d).

\footnotetext{
M. K. Ciołkowski

Department of Descriptive and Clinical Anatomy,

Biostructure Centre, Medical University of Warsaw,

Chałubińskiego 5,

02-004 Warsaw, Poland

M. K. Ciołkowski ( $₫)$

Department of Neurosurgery, Bielanski Hospital, Warsaw,

Cegłowska 80,

01-809 Warsaw, Poland

e-mail: maciej.ciolkowski@wum.edu.pl
}

However it is impossible to assess it from standpoint of non-native English speaker, some grammatical inconsequence in terminology can be noticed in the paper. As in the case of cavum Vergae, "Vergae" is a correct form of genetivus singularis from "Verga", in other cases, correct forms are cavum septi pellucidi and cavum veli interpositi. Otherwise it would sound better to add the preposition "of" before septum pellucidum and velum interpositum.

It would be also noteworthy to add to the discussed history of numbering the ventricles that Andréa Verga in his paper [2] recalled the old term "ventricle of Sylvius" for the cavum septi pellucidi and proposed term "aqueduct of the ventricle of Sylvius" for the channel connecting cavities located under the corpus callosum. Assuming he was the first to describe the posterior of these cavities, he proposed the terms "ventricle of fornix or sixth ventricle" as preferred by him.

Crura of the fornices with their commissure used to be known also as 'psalterium' due to their appearance. Subsequently, cavum Vergae is also sometimes called cavum psalterii. Verga gave an interesting footnote at this point, in which he (after Sabatier and Meckel) criticised translation of Greek ' $\psi \alpha \lambda$ i is' to 'lira', as it should be 'vault' or 'fornix' [2]. Thus, if we try to avoid eponyms and abandon pointless terms 'fifth' and 'sixth ventricle' and poetic 'cavum psalterii', the discussed space should be called cavum fornicis.

Yours sincerely, Maciej Ciołkowski

Open Access This article is distributed under the terms of the Creative Commons Attribution Noncommercial License which permits any noncommercial use, distribution, and reproduction in any medium, provided the original author(s) and source are credited. 

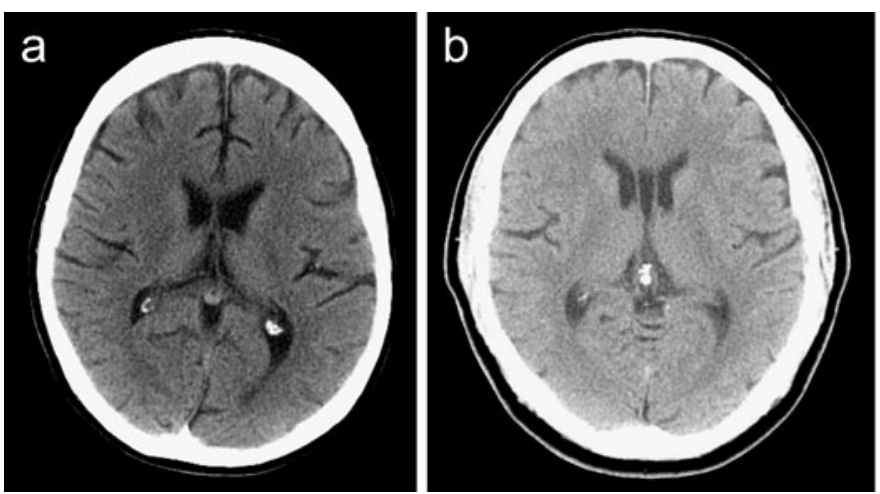

Fig. 1 Axial CT scans. a A 35-year-old male with the choroid plexus of the third ventricle visible behind almost completely fused septum pellucidum. b A 44-year-old male with the internal cerebral veins joined by the basal veins visible on both sides of the pineal body in

\section{References}

1. Tubbs RS, Krishnamurthy S, Verma K, Shoja MM, Loukas M, Mortazavi MM, Cohen-Gadol AA (2011) Cavum velum interposi-
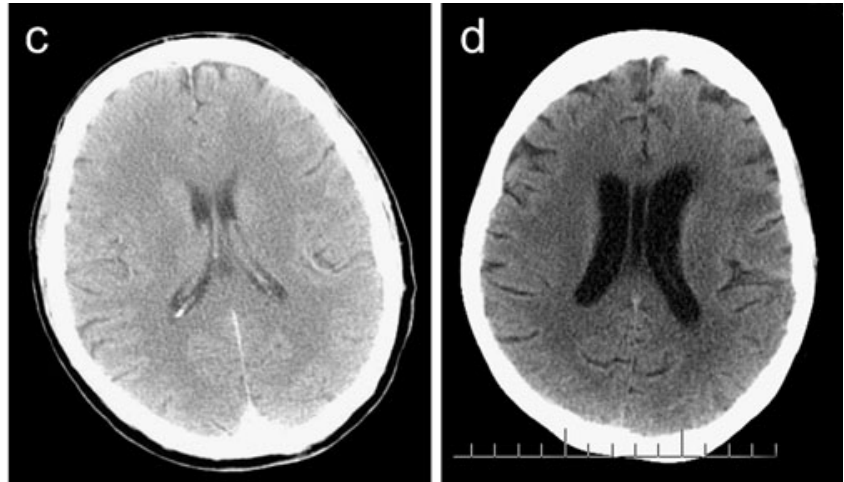

case of cavum septi pellucidi. c Another 44-year-old male with the crura of the fornices diverging under the splenium of corpus callosum in case without cavum septi or cavum Vergae. d A 67-year-old female with cavum septi pellucidi and cavum Vergae

tum, cavum septum pellucidum, and cavum vergae: a review. Childs Nerv Syst. doi:10.1007/s00381-011-1457-2

2. Verga A (1851) Sul ventricolo della volta a tre pilastri. Lettera del dottor Andrea Verga al dottor Ercole Ferrario. Gazetta Medica Italiana Federativa Lombardia 27:225-228 